\title{
O CONCEITO DE METRÓPOLE : Filosofia e forma urbana ${ }^{1}$
}

David Cunningham ${ }^{2}$

Trad. Luciana Rocha

Revisão de Silvia Pimenta Velloso Rocha

\section{RESUMO}

As últimas décadas vêm dando um novo significado ao papel da urbanização nas formas contemporâneas de acumulação do capital, trazendo à tona uma série de questões sócio-econômicas. O "urbano" aparece hoje como uma preocupação central nas ciências humanas e sociais, até mesmo, talvez, como um dos possíveis horizontes da sua convergência transdisciplina. A partir dessa constatação, o artigo procura investigar o conceito formal de metrópole, distinguindo-o dos estudos empíricos de caráter histórico ou sociológico e buscando compreender sua especificidade com relação às formas urbanas anteriores à metrópole (tais como a polis e a urbe).

\section{ABSTRACT}

The last couple of decades have accorded a new significance to the role of urbanization within contemporary forms of capital accumulation. This has brought to the fore a new series of socio-economic questions. The 'urban' appears today as a central concern across the entirety of the humanities and social sciences; even, perhaps, as one of the speculative horizons of their transdisciplinary convergence. Based on these ideas, the paper intends to investigate the metropolis as a formal structure, and to point out its specificity compared to the earlier urban forms (like the polis and the urbe).

Em que sentido teria o conceito do urbano encontrar, como Henri Lefebvre afirmava há trinta e cinco anos, uma "necessidade teórica"? Quais formas de "generalidade" transculturais e trans-disciplinares estariam em jogo aqui? E se isto é de fato, como Lefebvre sempre insistiu, uma questão de "necessidade de elaboração, uma busca de uma formulação conceitual", o que poderia uma filosofia crítica nos dizer, hoje, sobre que tipo de conceito o "urbano" é? ${ }^{1}$

\footnotetext{
${ }^{1}$ Publicado originalmente como The concept of metropolis: philosophy and urban form. Radical Philosophy, 133 . pp. 13-25. ISSN 0300-211X

${ }^{2}$, Department of English, Linguistics and Cultural Studies, Universidade de Westminster.
} 
Mesmo que a filosofia profissional nunca tenha parecido tão alienada de tais questões, o desdobramento social e espacial da realidade que provoca tais questões se revela, no nível mais básico, mais óbvio e urgente do que nunca. Pela primeira vez, cerca de 50 por cento da população mundial - mais do que toda a população mundial em 1950 - habita agora o que é convencionalmente definido como espaço urbano,. Dentro dos próximos anos, espera-se pelo menos vinte mega-cidades com populações superiores a 10 milhões localizadas em todas as áreas do globo. Desde 1950, quase dois terços da população do planeta em crescimento foi absorvida pelas cidades. Até 2020 , 0 total da população rural provavelmente começará a cair, o que significa que todo o crescimento futuro da população, efetivamente, será um fenômeno urbano. O ritmo deste processo não pode ser subestimado, tanto em termos gerais quanto em termos particulares. Lagos, por exemplo, que tinha em 1950 uma população total de 300.000 habitantes, hoje tem 10 milhões. Ao mesmo tempo, este desenvolvimento incrivelmente rápido também implica novas formas de urbanização, quer seja o chamado "corredor" urbano do Rio das Pérolas e deltas do rio Yangtzé, a proliferação das favelas da África subsaariana, ou os aproximadamente 130 mil quilometros litorâneos de casas de veraneio e resorts de lazer ao redor de Málaga, que, como tem sido sugerido, pode muito bem ser uma base para a futura megalópole. Na medida em que isso indica uma sociedade global emergente na qual, Lefebvre especulava, a "problemática urbana torna-se predominante", essa condição implica, então, não apenas a expansão quantitativa, mas também mudanças qualitativas - transformações no âmbito das relações entre o urbano e o rural, mas também, cada vez mais, dentro e entre diferentes formas urbanas, processos de urbanização e as forças heterogêneas que os geram. O potencial de generalização social, cultural e tecnológica produtiva em escala planetária, e as redes concretas de intercâmbio e de interação que cada vez se ligam a espaços urbanos não contíguos dentro da unidade diferencial de uma economia global, abrem historicamente um novo conjunto de relações entre o universal e o particular, a concentração e a dispersão, que claramente exigem novas concepções de mediação.

Se isso de fato sugere uma certa "necessidade teórica", então é evidente que não dispomos de muitas "teorias" sobre o urbano. "O início do século XXI" é, como os editores de um número crescente de publicações sobre estudos urbanos colocam, "um momento emocionante para aqueles que querem entender a cidade. ${ }^{2}$ Certamente, o contexto sociológico de uma posição do positivismo urbanista-tecnocrata dominante após a Segunda Guerra Mundial, em que Lefebvre fez a sua intervenção inicial, parece cada vez mais distante, tanto por sua conexão histórica com aparelhos do Estado que foram progressivamente marginais, quanto por formas emergentes de desenvolvimento capitalista, porque era desacreditado dentro da arena intelectual. Enquanto a literatura empírica sociológica sobre as cidades continua a crescer, ela é agora acompanhada por uma visão um pouco 
diferente dos estudos urbanos, formada a partir de uma retomada do interesse pela obra de escritores como Benjamin e Kracauer, bem como os situacionistas e o próprio Lefebvre. Estudos acadêmicos de peso sobre o desenvolvimento histórico da cidade enchem os catálogos das editoras ao lado de "biografias", "guias secretos" góticos e histórias culturais pitorescas de grandes centros urbanos, como Paris, Londres, Nova York e Los Angeles. Ao mesmo tempo, essa predominância contemporânea da "problemática urbana" tem ajudado a conferir um novo significado teórico geral, e uma nova valência política, a órgãos específicos do conhecimento, em particular a geografia - como assunto de uma reconstrução disciplinar, a partir dos escritos de David Harvey, Neil Smith e outros; tem ajudado ainda a promover um renovado interesse pela arquitetura e pela teoria arquitetural, oferecendo um acesso privilegiado às características distintivas da nossa época atual, a partir da esfera da produção cultural. Grande parte da obra de Fredric Jameson desde o início de 1980 pode, por exemplo, ser pensada como formando e sendo formada por uma tal conjuntura teórica.

Isto tem ajudado a promover uma mudança mais ampla na cultura política de inspiração marxista. Se o "urbano" pouco aparece como uma temática específica dentro das obras "canônicas" de Marx e Engels, após o final de 1840, com os diversos movimentos de "socialismo" no século XX, este vácuo tendeu a ser preenchido por uma série de concepções profundamente antiurbanas acerca das condições de lutas políticas, sociais e espaciais. A cidade, como Régis Debray afirma citando Castro, é "um cemitério de revolucionários e recursos" - um juízo político que decorre dos modelos maoísta, cubano e outros modelos latino-americanos de luta social e divisão. ${ }^{3}$ Isso também ocorre, embora de forma mais complexa, e apesar das várias experiências no urbanismo e na arquitetura das primeiras vanguardas metropolitanas, com o modelo Soviético, que manteve desde o princípio uma suspeita essencial em direção ao desenvolvimento metropolitano. Em grande parte da teoria marxista ocidental, esse juízo associou-se a argumentos sobre o primado da industrialização e da fábrica sobre quaisquer processos autônomos de urbanização - dentro das "leis de movimento" do desenvolvimento capitalista, e na composição do proletariado como força oposta a este. A abordagem althusseriana precoce de Manuel Castells sobre a "Questão Urbana" (em 1977) poderia ser entendida como um somatório estruturalista da então clássica posição "ortodoxa", desenvolvido em explícita oposição à "fetichização" da revolução urbana sugerida por Lefebvre em 1968 e suas reconsiderações sobre a forma revolucionária da Comuna de Paris. ${ }^{4}$

O último par de décadas tem concedido um novo significado para o papel da urbanização dentro das formas contemporâneas de acumulação do capital. Isto trouxe à tona uma nova série de questões sócio-econômicas, relativas à especulação imobiliária, por exemplo, monopólio e financiamento do capital e sua relação com uma teoria marxista ortodoxa do valor. Isso renovou o foco sobre o papel das lógicas de produção e das relações sociais, 
específicas da urbanização - como lógicas não redutíveis ao "industrial" - e sua conexão com a estruturação espacial contemporânea dos fluxos cada vez mais globalizados de informação, dinheiro e pessoas. Antes aparentemente desvalorizado no mercado acadêmico, o "urbano" aparece hoje como uma preocupação central nas ciências humanas e sociais, até mesmo, talvez, como um dos possíveis horizontes da sua convergência transdisciplinar.

É na amplitude de questões teóricas e políticas levantadas por essa convergência que são abordadas as observações a seguir. Elas procuram indicar a necessidade de uma maior reflexão crítica sobre os específicos termos transdisciplinares dos "estudos urbanos", em particular, uma reflexão sobre caráter conceitual das diferentes "figuras" através das quais a especificidade sócio-histórica e espacial da forma urbana contemporânea tem sido articulada nos vários campos em que está envolvida. Pois, como Lefebvre observou, se o fenômeno urbano é realmente "universal" - isto é, "uma realidade global" - o problema do urbano levanta, de forma particularmente urgente, a questão das formas de universalidade que estão em jogo na teoria crítica contemporânea, em geral, bem como suas relações com conhecimentos mais especializados com formas de particularidade cultural.

Enquanto o pensamento acerca desses processos precisa dirigir a sua atenção para o caráter sistemático da problemática urbana contemporânea no planeta, tal projeto poderia ainda, como pretendo sugerir, encontrar o seu compasso em seus primórdios teóricos, em uma releitura de dois pensadores canônicos da forma urbana: Lefebvre e Georg Simmel. Assim, devemos a Lefebvre e Simmel - a cada um de modo diferente - a tarefa inacabada de pensar um conceito filosófico do urbano juntamente com um relato histórico de suas emergentes formas espaciais e sociais. A elaboração adequada desta tarefa está além do escopo deste artigo. Pretendo em vez disso um prolegômeno mais modesto: um questionamento breve, e necessariamente esquemático, sobre um conceito histórico particular da forma urbana - a metrópole - que tem desempenhado um papel persistente dentro de certos discursos interdisciplinares sobre a experiência social e espacial modernas. Os riscos de acusação de um certo anacronismo, de muito peso na opinião atual, parecem sugerir, não sem razão, que a metrópole é uma forma do urbano, que está em processo de tornar-se historicamente superada em uma era da chamada sociedade em rede. No entanto, independentemente desta verdade talvez mais complicada do que parece - as afirmações repetidas de que o conceito de metrópole tem, historicamente, significado (ontológico e fenomenológico) universal, são precisamente o que torna esse conceito de filosoficamente interessante. Essa universalidade, por sua vez, tornou-se um ponto-chave da mediação teórica entre uma gama de diferentes disciplinas e permitiu sua construção enquanto uma espécie de "figura privilegiada" na modernidade capitalista em si - para a arte, arquitetura ou história literária tanto 
quanto para a teoria social - persistindo com Simmel, Sombart, Benjamin ou Meidner, passando por Rem Koolhaas. ${ }^{5}$

O que se segue, então, é uma genealogia conceitual que busca evidenciar a lógica histórica do conceito de metrópole. Se este é essencialmente um processo "filosófico", ele também se abre para algumas questões políticas contemporâneas, a que retornarei mais adiante. Antes, porém, é necessário dizer algo sobre a compreensão "filosófica" que é inerente a "necessidade" de algo como uma filosofia do conceito de urbano. Isto irá fornecer um contexto para minha primeira questão: que o interesse filosófico do conceito de metrópole está em tanto em sua apresentação como uma negação determinada da cidade quanto uma forma específica do urbano.

\section{Filosofia, cidade, metrópole}

Embora isso seja pouco lembrado, Lefebvre é explícito ao afirmar que, a fim de "começar uma análise crítica e aprofundar a problemática urbana", é a filosofia que deve ser "o ponto de partida."6 No entanto, se os estudos urbanos aparecem hoje como um campo interdisciplinar por direito próprio, que a da "filosofia" - em oposição à ciência social ou à teoria cultural, onde o trabalho de Lefebvre, como o de Simmel, tem sido recebido de forma mais fácil - possa contribuir para um conhecimento do urbano está longe de ser óbvio. Em outro sentido, no entanto, a base para tal contribuição é por demais evidente, e, como tal, potencialmente enganosa. Pois em sua clássica "origem", a própria filosofia é muito precisamente situada na cidade (polis). Na verdade, para Platão, se o "objeto da política é a unidade da cidade", então, como afirma Jean-François Pradeau, o conhecimento que é adequado a esse objeto é a filosofia. A cidade é o ponto em que a filosofia de Platão converge em um todo, e não apenas na República. O "destino do conhecimento [da verdade] e o da vida em comum [cidade]" estão intrinsecamente conectados. ${ }^{7}$ Isto significa não apenas que é o pensamento filosófico o responsável pela fundação e governo de um ser comum, que constituiria "a unidade de uma e mesma cidade", mas que não pode haver pensamento sem a polis. O mito do "rei-filósofo" - não uma expressão a ser encontrada na obra de Platão - nos afasta do ponto mais importante. A filosofia, em sua determinação clássica grega, é irredutivelmente urbana. Assim, para Aristóteles, também, a natureza única do homem como animal político [zoon politikon] - concepção retomada mais tarde por Marx, entre outros - corresponde àquele "cuja natureza é viver em uma polis." Enquanto "a associação que assume a forma de uma polis (to hou heneka), como a condição da "boa vida", é determinada ideologicamente - como "as razões pelas quais o homem é concebido pela natureza - é a reflexão filosófica, bem como a "observação", que são necessárias para a descoberta de como esta "boa vida" é melhor alcançada. ${ }^{8}$ A filosofia, portanto, deve ter como tarefa central a elaboração de uma definição de "ambos, a cidade e o conhecimento que toma a cidade como um objeto". ${ }^{9}$ 
Estes discursos filosóficos sobre a cidade lançaram uma sombra histórica longa e diversa, passando pela teologia medieval, pelo humanismo renascentista e pelo racionalismo lluminista (onde a idéia de 'planejamento urbano' como tal se inicia) ${ }^{10}$, e além. É uma história que, de várias formas, a filosofia moderna tem frequentemente procurado recuperar, mesmo se isso perturba sua identidade como disciplina moderna. No entanto, como nos lembra Lefebvre, tais discursos emergem e adquirem a sua validade apenas dentro da forma urbana historicamente específica da polis em si - que distingue formas espaciais e sociais de relacionalidade ou 'associação' estabelecidas pelo que Edward Soja chama de Segunda Revolução urbana, a começar nos planos aluviais dos rios Tigre e Eufrates. ${ }^{11}$ Soja sustenta que até a Terceira Revolução Urbana constituída pelo "Capitalismo urbano-industrial", a forma da cidade-estado era elaborada, difundida e reinventada em todo o mundo com relativamente poucas mudanças nas especificidades de seu espaço fundamental. Quer se admita ou nao isso, se alguém aceita que essas "especificidades espaciais" não são as da forma urbana moderna - e que a formação da "filosofia" em si não pode ser separada das relações sociais e da divisão do trabalho dentro da qual é (re) constituída - então é claro que não se pode aceitar que isso não muda a filosofia e suas relações visando uma definição "da cidade e do conhecimento que toma a cidade como seu objeto". O reconhecimento de sua distância em relação à forma urbana da cidade é a condição para qualquer engajamento filosófico crítico com a problemática urbana moderna. É na sua capacidade em marcar tal reconhecimento que o conceito historicamente específico de metrópole - que surge no início do século XIX tanto evocando seu significado clássico ("cidade mãe") quanto radicalmente divergindo deste ${ }^{12}$ - adquire o que considero seu potencial interesse filosófico. Podemos encontrar uma base para essa genealogia conceitual no trabalho do filósofo italiano Massimo Cacciari, que, com o trabalho "The dialetics of the negative and the metropolis" (1973) - e as leituras marcantes de Simmel, Weber, Tonnies, Benjamin e outros - tem procurado precisamente elaborar algo como uma teoria da metrópole, algo mais do que mera história cultural. ${ }^{13}$ Como Cacciari mostra, enquanto cada um dos grandes teóricos do início do século XX pode recuar diante de suas implicações mais radicalmente "negativas" da "imagem" da metrópole, esta aparece repetidamente em seus escritos de forma notavelmente consistente:

(...) um desenraizamento dos limites das urbes, a partir dos círculos sociais dominantes dentro dela e de sua forma - um desenraizamento do lugar (como um local de habitação) ligado à habitação. A cidade se afasta ao longo das ruas e eixos que se cruzam com a sua estrutura. Como exato oposto do Holzwege de Heidegger, ela conduzem a um não-lugar. Os sociólogos dos grandes centros urbanos do século compreenderam perfeitamente o desenraizamento da importância da radiação explosiva da cidade. ${ }^{14}$ 
É com o desenvolvimento da forma conceitual de tal 'desenraizamento', da forma-cidade, e de sua determinação fenomenológica do 'lugar', que chegamos à construção familiar da metrópole como uma alegoria ou uma figura da modernidade capitalista, o lugar essencial da experiência moderna de Baudelaire, Benjamin e Debord. Cacciari está sem dúvida correto ao estabelecer o famoso ensaio de Simmel, "A Metrópole e a vida mental", como o pivô (certamente o momento mais influente) nesta história. Pois um aspecto marcante do ensaio de Simmel é que a metrópole é conceitualmente elaborada não em contrapartida à vida rural, como se poderia esperar, e sim à vida da cidade na "Antiguidade e na Idade Média". Esta é a base fenomenológica poderosa da vida social moderna definida, negativamente, em termos de deslocamento das «restrições» impostas por tais formas urbanas anteriores. Se Simmel traz isso de forma mais clara e sucinta, tal contraste não foi único entre os seus contemporâneos. O ensaio de Simmel foi escrito como uma palestra antes da Exposição Metropolitana alemã em Dresden no ano de 1903. Outras palestras na mesma série, tal como a do historiador Karl Bücher, igualmente enfatizaram, como mostrou David Frisby,, uma idéia historicamente específica da metrópole como um "novo tipo urbano, no qual nenhuma forma anterior da cidade se compara", habitada por novas espécies. Se o crescimento quantitativo é importante aqui, é apenas em termos de diferenças qualitativas que tais questões são compreendidas. (Karl Scheffler escreveu em 1910: "o que é absolutamente determinante para o conceito de metrópole moderna não o número de seus habitantes, mas sim o espírito da metrópole" [Grossstadt Geist].) ${ }^{15}$

Parte da lógica para a exposição de 1903 foi uma tendência antimetrópole na virada do século na cultura européia, cuja marca não foi necessariamente o antiurbano em si mesmo. Para cada Gemeinschaft rural, desdobrando-se frequentemente em ideias sobre a "cidade jardim", podemos encontrar uma visão contemporânea da cidade como polis ou urbe, contraposta à "nova forma urbana" da metrópole. Superar a "negatividade da metrópole", começando talvez com o próprio Simmel, significa sempre voltar a reduzi-la à regressiva "utopia" da cidade. ${ }^{16}$ (Patrizia Lombardo, por exemplo, aponta a exemplar La cité antique de Fustel de Coulanges como um lugar utópico além das 'contradições modernas'; tanto Cacciari quanto Manfredo Tafuri se referem ao exemplo posterior, e aparentemente mais progressivo, do Deutsche Werkbund e a uma interseção com o que Lacoue-Labarthe descreve como o sonho da própria cidade como uma obra de arte; a polis como pertencente à esfera da techné ${ }^{17}$ ). Assim, o conceito de metrópole pode ser desenvolvido historicamente não como um simples sinônimo de cidade e da linhagem antiga que esta designa, mas, ao contrário, como a manifestação de uma lógica espacial e produtiva caracteristicamente moderna, que se opõe a e desestabiliza esse cenário. Como tal, o conceito só se molda conceitualmente ao final de um processo durante o qual as velhas formas urbanas explodem. ${ }^{18}$ 
É em tais termos históricos e conceituais que o ensaio de Simmel deve ser entendido. Ao contrário da sociologia e da história urbana da Chicago School ou Lewis Mumford, o estudo de Simmel não é dedicado a uma simples delimitação ou agregação de exemplos do urbano. Embora a sua metrópole seja, em algum nível, evidentemente Berlim (assim como 'sociedade urbana' de Lefebvre é, em certo sentido, Paris), a problemática urbana fora esboçada precisamente com a articulação possível, na cultura atual, de formas universais de relacionalidades sociais e espaciais, e as experiências produzidas por tais relações constituem o que Cacciari chama de "o problema da relação entre a existência moderna e suas formas"19 Mesmo se nossa leitura nos leva para além dos limites da própria apresentação de Simmel, já encontramos, no ensaio de 1903, a metrópole não apenas como um conceito "sociológico" mas também efetivamente histórico-filosófico.

\section{Filosofia, abstração, forma urbana}

A impossibilidade de reconstituir uma verdadeira "filosofia da cidade" implica a necessidade de aprofundar a relação entre "modelo conceitual" historicamente novo da forma urbana (que, por razões complexas, o termo metrópole passou a marcar) e o destino moderno da própria filosofia. É importante considerar, por exemplo, a forma conceitual do que Robert Ackermann delineia como Cidade de Wittgenstein - uma noção que deriva de uma famosa analogia nas Investigações Filosóficas:

Você quer dizer que elas por isso não são completas, então pergunte-se se a nossa linguagem é completa; se 0 foi antes que the fossem incorporados 0 simbolismo químico e a notação infinitesimal, pois estes são, por assim dizer, os subúrbios de nossa linguagem. (E com quantas casas ou ruas uma cidade começa a ser cidade?) Nossa linguagem pode ser considerada como uma velha cidade: uma rede de ruelas e praças, casas novas e velhas, e casas construídas em diferentes épocas; e tudo isso cercado por uma quantidade de novos subúrbios com ruas retas e regulares e com casas uniformes. ${ }^{20}$

Aqui, a heterogeneidade dos jogos de linguagem - sem síntese - que constitui o espaço urbano moderno, tanto metaforicamente quanto realmente, deve ser concebida de uma forma bastante diferente dos clássicos da filosofia com relação à polis, que supõe uma a unidade teórica fundamental do conhecimento que organizaria a cidade. ${ }^{21} \mathrm{Em}$ certo sentido, a cidade de 
Wittgenstein pode ser lida como uma metáfora simples para a história familiar da perda progressiva da filosofia moderna para os 'domínios' emergentes das diversas ciências independentes - os jogos de linguagem que incluem "o simbolismo da química e da notação do cálculo infinitesimal", e também "a multidão de novos bairros" que são as ciências sociais. Ao mesmo tempo, na medida em que isso implica, entre outras coisas, a questão real, "tanto a cidade e o conhecimento que toma a cidade como seu objeto" tornam-se mais do que apenas uma metáfora. ${ }^{22}$

É precisamente esta questão que Lefebvre levanta tanto em O Direito à Cidade (1967) quanto em uma das seções de Revolução Urbana. Vale a pena observar o que ele tem a dizer. Começando com uma característica hegelianomarxista, um ataque a um positivismo urbanista e à produção de um conhecimento "fragmentário" e acrítico, Lefebvre ressalta que tal positivismo se apresenta como um contrapeso à filosofia clássica. Mas logo que tenta estender suas propriedades, esse positivismo tende sempre (como modelos linguísticos) para um movimento involuntário e irrefletido de especializações da "ciência" para as generalidades da "filosofia", em virtude de uma necessária reivindicação, consciente ou não, sobre a totalidade:

\begin{abstract}
Assim como insistimos na totalidade, nós estendemos a filosofia clássica, destacando seus conceitos (síntese, totalidade), a partir dos contextos e arquiteturas filosóficas que surgiram e tomaram forma. $\mathrm{O}$ mesmo é verdade para os conceitos de sistema, ordem, desordem, realidade e possibilidade (virtual), objeto e sujeito, determinismo e liberdade, estrutura e forma, função e conteúdo. Podem estes conceitos serem separados de seus desenvolvimentos filosóficos? ${ }^{23}$
\end{abstract}

A questão aqui é a necessidade de conceitos gerais, como pontos de mediação entre os diferentes jogos de linguagem e os conhecimentos específicos. ${ }^{24}$ O fenômeno urbano, "tomado como um todo, não pode ser compreendido por qualquer ciência especializada ". ${ }^{25}$ Daí a "necessidade teórica" - ainda que apenas uma base para uma hipótese especulativa do todo - de uma reflexão filosófica mais ampla. Pois a filosofia, Lefebvre escreve, historicamente "sempre buscou a totalidade".

Isso significa duas coisas. Primeiro, se a filosofia permanece necessária devido à "necessidade teórica" de totalidade, mesmo assim ela não pode retornar, após a emergência das "ciências especializadas", à sua forma anterior como uma unidade de determinado conhecimento teórico. A busca de uma elaboração conceitual não pode ser entendida como uma reconstrução anacrônica da abordagem que a filosofia clássica faz da cidade, mas sim como a procura de uma forma filosoficamente reflexiva de transdisciplinaridade que permita manter um horizonte especulativo de totalidade em relação a um conhecimento teórico da forma urbana moderna. (A filosofia é, em Lefebvre remodelada como um projeto de totalidade que, todavia, "a filosofia como tal, não pode realizar".). Nas palavras de Lefebvre, "quando a filosofia tentou alcançar ou realizar a totalidade utilizando seus próprios recursos, ela falhou [...] [até porque] forneceu esse escopo e essa visão". ${ }^{26}$ Contra as compartimentalizações de um "conhecimento fragmentado" (parcelado até 
entre as ciências sociais e estudos culturais particularistas da população urbana), a tarefa torna-se estabelecer um movimento interdisciplinar que resgataria o viés universalizante do conhecimento filosófico. O segundo ponto é que isso exige uma justificação para as formas de abstração que tal projeto de totalidade implica - contra a exigência empirista de uma volta imediata ao "concreto", personificada por certas "sociologias" urbanas. Isso pode muito bem estar nas formas distintas de abstração social com as quais a modernidade capitalista se relaciona. ${ }^{27}$

Vamos continuar a seguir o desenvolvimento do próprio argumento de Lefebvre. Se a problemática urbana moderna exige conceituação, afirma Lefebvre, é porque ela deve, nesse sentido teoricamente universal, ser considerada, em primeiro lugar, como essencialmente uma questão de "forma pura: por um espaço de reunião, encontro, simultaneidade". Como tal, Lefebvre continua, "sem nenhum conteúdo específico". O urbano é uma abstração, mas ao contrário de uma entidade metafísica, é uma abstração concreta, associada à prática." ${ }^{28}$ Essa noção aparentemente paradoxal de uma "abstração concreta", Lefebvre elabora, naturalmente a partir de Marx; uma "inspiração" que, relaionada ao conceito mais amplo de espaço social, é desenvolvida em seu livro mais conhecido, A produção de espaço (1974).

\begin{abstract}
Em sua preparação para O Capital, Marx foi capaz de desenvolver conceitos tão essenciais como o de trabalho. Trabalho tem existido em todas as sociedades, assim como representações dele, mas só o século XVIII fez emergir o conceito em si. Marx mostra como e por que isso acontecia, e então ele prossegue ao essencial, que não é nem uma substância nem uma 'realidade', mas sim uma forma. Inicialmente, Marx descobre uma forma (quase) pura, de circulação de bens materiais ou troca. Esta é uma forma quase-lógica semelhante, e de fato ligada com, outras "puras" formas (identidade e diferença, coerência, a equivalência, a reciprocidade, a recorrência, e repetição) como uma abstração concreta, que é desenvolvida por meio do pensamento - exatamente como ela se desenvolveu no tempo e espaço - até que ele atinja o nível de prática social: através de dinheiro, trabalho e seus determinantes. Este tipo de desenvolvimento culmina na noção de mais-valia. O pivô, entretanto, permanece inalterado: em virtude de um paradoxo dialético, este pivô é um quase vazio, uma quase ausência - ou seja, a forma de intercâmbio, que rege a prática social. ${ }^{29}$
\end{abstract}

Lefebvre segue o movimento da famosa introdução metodológica dos "Grundrisse" de Marx - por sua vez, como se sabe, devedora da Ciência da Lógica de Hegel. A articulação da forma urbana como uma abstração concreta é moldada aqui no "tipo de desenvolvimento" do conceito que (mais proveitoso do que a dedução clássica, e mais flexível do que indução ou construção) conduz a um pensamento, através de determinantes, em direção à "rica totalidade" das relações e mediações que constituem a (concreta) prática social, na qual o pensamento se apropria do concreto, para ser reproduzido como intelectualmente concreto". ${ }^{30}$ Nesse processo, como um recente comentarista diz: "em seu desenvolvimento em direção a um conceito, não mais imediato e empírico, mas conceitualizado e determinado, o abstrato, subsiste no entanto como condição de sua conceituação. ${ }^{31}$ 
No entanto, no ponto de vista de Lefebvre, essa epistemologia da abstração concreta se desdobra em - ou mesmo se confronta com (como, aliás, o próprio "Grundrisse" faz) uma problemática diferente: a das abstrações reais (ou, em última instância, o que Peter Osborne chama atuais). ${ }^{32}$ Estas são duas diferentes "formas" de abstração que Lefebvre tende a confundir. Se ambas derivam, via Marx, da lógica de Hegel, elas não são idênticas ou radicalmente semelhantes no que diz respeito às implicações sobre um conceito de forma urbana tal como visado por Lefebvre. Isto é verdadeiro quando tal forma é considerada em relação à sua manifestação historicamente específica dentro da modernidade capitalista, que estou designando pelo conceito de metrópole. Pois o que são denominadas aqui abstrações reais - uma abstração não apenas como categoria mas como realidade, como Marx começa a formular nos Grundrisse - não seriam nem generalizações intelectuais, nem aspectos metodologicamente necessários de uma epistemologia da concretização, mas aqueles que, no conjunto específico de circunstâncias da modernidade capitalista, passaram a ter um objetivo real de existência social, "uma forma social definida", ainda que "girando" em torno de um "quase vazio".

Lefebvre escreve: como forma lógica "pura", a forma urbana pede por um "conteúdo e não pode ser concebida como sem conteúdo, mas, graças à abstração, tal contexto é concebido, precisamente, como independente de qualquer conteúdo específico".. ${ }^{33}$ Talvez uma certa ambiguidade neste frase "graças à abstração" - possa nos ajudar a esclarecer algo da distinção entre abstração concreta e real. Seu significado mais óbvio é que, graças à abstração, como parte de uma metodologia do processo, podemos analisar o espaço urbano como uma "forma pura", intelectualmente abstraída de sua diversidade, de seus conteúdos materiais reais, mas conceitualmente desenvolvidos tendo em vista um todo "concreto". Mas é claro que alguém poderia dizer, seguindo $O$ Capital, que, na modernidade capitalista, é de fato "graças" à sua forma de abstração que a troca, na negação determinada da "substância" do valor de uso, é sem conteúdo e "não determina o que é trocado". Isso é a realidade da "forma pura" da troca de mercadorias, da forma do valor e do dinheiro, e assim, possivelmente, de seus aspectos espaciais característicos. Quanto à forma-valor, o teórico Christopher Arthur diz:

\footnotetext{
Há um vazio no coração do capitalismo. O que é constituído quando as características do material heterogêneo das mercadorias são declaradas ausentes de sua identidade como "valores" é uma forma de unidade de mercadorias esvaziada de conteúdo pré-determinado. Só pode ser caracterizada como forma, como tal, a forma pura da permutabilidade. É a forma de troca que é o determinante primário da economia capitalista, em vez do conteúdo por ela regulamentado. ${ }^{34}$
}

Esta forma de permutabilidade - quando atinge o ponto de "valor de auto-valorização" - não tem limite natural (quanto ao que pode ser trocado). Como tal, a sua capacidade para "assumir" qualquer "conteúdo específico" 
confirma seu estatuto, conceitualmente, como uma forma pura que de fato "rege a prática social".

A equação da forma urbana de Lefebvre, juntamente com a "descoberta" de Marx da forma pura da troca coloca as seguintes perguntas. Como a troca, especificamente a troca monetária, que não determina formalmente "o que é trocado"- teria o fenômeno urbano moderno uma afinidade especial e real com as formas lógicas? ${ }^{35}$ Se assim for, em que grau e em que sentido poderia a "abstração" do conceito de metrópole ser conectada à «abstração» da forma (do urbano), com a qual está relacionada? ${ }^{36}$ De fato, seria o reconhecimento da abstração uma condição para qualquer pretensão de captar a sua especificidade histórica?

Lefebvre volta atrás nas implicações mais radicais de tais questões. Na verdade, ele finalmente se concentra no que considera o "diferencial" do "desenvolvimento" conceitual dos Grundrisse sobre o de O Capital: este, apresentado como 'empobrecedor' por causa de sua estrutura estritamente formal - focado na forma "quase pura" do valor - em comparação com a abertura do primeiro aos temas mais concretos e às condições mais práticas. ${ }^{37}$ No entanto, estes riscos causam mal-entendido sobre o que está em questão na lógica da "estrutura formal" do Capital, na medida em que ele gira em torno da abstração real da forma-valor como o que define a especificidade histórica do capitalismo como tal. É significativo, então, que, seguindo 0 desenvolvimento estrutural da própria obra de Marx, é a "abstração ruim" do trabalho abstrato (tempo), em vez da forma-valor, que Lefebvre toma como ponto de partida para a discussão da abstração através da qual o conceito chave de "espaço abstrato" é elaborado em A Produção do Espaço. No entanto, como Arthur assinala, é "a forma de troca que estabelece a síntese social necessária em primeiro lugar". ${ }^{38}$ É o capital e não o trabalho que, analiticamente, no mínimo, tem prioridade aqui. Desconhecendo isso, Lefebvre parece tentar adotar uma noção de espaço abstrato como algo parecido com as formas meramente sociais da aparência do "concreto" e as relações espaciais de produção e experiência.

No entanto, não é verdade que o próprio "espaço abstrato" deve ser entendido como a condição de produção "real" do espaço - e das relações espaciais - formadas, acima de tudo, em termos de uma produção para a troca, como parte de uma "subsunção real" à autoprodução de valor? Se assim for, uma certa forma abstrata de relacionalidade seria o "conteúdo" real do espaço abstrato - a condição de uma nova lógica espacial da conectividade e da "vida" social - um "conteúdo comum" que não é fornecido previamente (uma simples abstração fora do conteúdo), mas sim uma espécie de "introjeção" desta forma. ${ }^{39}$ Talvez seja isso que, acima de tudo, defina a problemática conceitual da metrópole. 


\section{Cidade do dinheiro}

Em nenhum lugar nos estudos de Lefebvre, Simmel é referido, mas há um ponto óbvio de proximidade com as preocupações do ensaio de 1903. A metrópole, Simmel escreve, é "a sede do e é dominada pela economia do dinheiro, definida por sua "multiplicidade" e concentração dos direitos econômicos de troca. É o dinheiro, com toda sua falta de cor e indiferença, que passa a ser o denominador comum de todos os valores na metrópole; que irremediavelmente esvazia o núcleo das coisas, sua individualidade, seu valor específico, e sua incomparabilidade. Todas as coisas flutuam com gravidades específicas similares. ${ }^{40}$ A metrópole seria assim, para Simmel, a formação espacial historicamente específica das "diferenças que, como a medida e cálculo de valor, integram cada fenômeno na dialética do valor abstrato". ${ }^{41}$ No entanto, devemos observar, nesta relação com a economia de dinheiro, que a metrópole aparece de duas diferentes maneiras nos estudos de Simmel: como sua «sede» e como aquilo que é próprio dos "dominados" pela sua forma. No primeiro caso, a metrópole é entendida como o "suporte material" da política monetária de câmbio, o espaço principal em que a troca acontece. No segundo, a metrópole designa o processo geral pelo qual o próprio espaço é formado ou produzido pela troca (de uma forma que desloca ou expele seu valores de uso específicos, sua "incomparabilidade"). Como diz Cacciari, Simmel encontra na Metrópole "a forma geral assumida pelo processo de racionalização [e abstração] das relações sociais" ${ }^{42}$ Essas duas relações com a economia de dinheiro não são separáveis, e de fato são, em certo sentido, mutuamente condicionadas, mas é a natureza desta generalidade que precisa ser interrogada. Conceitualmente, então, a metrópole é moldada, em sua "forma pura", como constituída por - e representativa das - formas distintas (e contraditórias) de abstração real, que são inerentes às relações sociais da modernidade capitalista. Metrópole seria um nome para a formação espacial generalizada de uma certa realidade de formas puras - a correlação espacial, principalmente, da mediação da troca monetária e da produção do social - que, negando a forma urbana da cidade, constituiu sua própria lógica de desenvolvimento. Se a metrópole é "uma forma quase-lógica", é enquanto uma forma que une um conjunto diferencial no qual cada lugar particular se torna equivalente num processo de trocas e circulação universais. É isto que constitui sua afinidade com o conhecimento filosófico, como uma forma similar e solidária ,como afirma Lefebvre, a outras formas puras (identidade e diferença, coerência, equivalência, reciprocidade e repetição). Lembremos: foram as formas lógicas da identidade e diferença que constituíram o terreno "filosófico" da disputa clássica de Platão e Aristóteles sobre a polis. ${ }^{43}$ No entanto, qualquer conceito de forma urbana corre o risco de ser reificado como um mero formalismo, se não for feita a mediação recíproca de um relato da evolução 
espacial e processos histórico-sociais pelos quais tais formas são reproduzidas. Daí então, a necessidade de uma transdisciplinaridade na formação de um projeto de totalidade, que a filosofia em si não pode realizar, e que depende da interseção colaborativa de uma série de formas de conhecimento que buscam traçar as relações intersetoriais da própria metrópole. ${ }^{44}$

Se, portanto, a metrópole apresenta-se como uma forma de abstração (real) e apenas como tal é "unificada", ela só atinge a "existência real", e, portanto, "forma" e "conteúdo" específicos e variáveis - como ocorre, em princípio, com qualquer espaço social - em virtude da produção espacial de sua totalidade aberta e dispersa de um conjunto de materiais específicos, de sua particular "variedade de relações", de suas próprias transações múltiplas e contatos, que são eles mesmos altamente diferenciados e relacionados à sua forma geral. ${ }^{45}$ De fato, sem isso não há qualquer forma concreta ou "significado" determinado. Mas, em contraste com as formas que Lefebvre chama de "absolutas" e o espaço "histórico" - em que, como na polis, a "incomparabilidade" das qualidades intrínsecas de determinados lugares continuam a ser essenciais - os "valores específicos" não mais definem o urbano como tal, mas são constitutivamente mediados por uma forma pura de intercambialidade. Fenomenologicamente, se a metrópole tem um conteúdo universal é o que Cacciari chama de "sem morada", o conteúdo de uma estrutura da experiência histórica em que "a morada" - a grande temática heideggeriana - só aparece como uma forma "ausente", uma projeção nostálgica de valores e pertencimento irrecuperáveis. Uma análise sóbria e lúcida do "problema da relação entre a existência moderna e suas formas" só poderia ser construída no nível de uma mediação 'universal' da irredutível realidade fenomenológica da abstração na metrópole, e portanto, da sua formação histórica da vida sócio-espacial e da subjetividade. ${ }^{46}$

Em sua apropriação padrão pelas teorias culturais, literárias e da arte, a tendência tem sido garimpar no ensaio de Simmel uma espécie de tipologia historicista e impressionista dos fenômenos urbanos: o tipo blasé, o intelectualismo urbano e assim por diante. No entanto, na rede sistemática de relações que constituem o ensaio em si, estes fazem sentido precisamente como aspectos múltiplos, e muitas vezes conflituosos de uma lógica de abstração que não pode ser esgotada. Assim como, digamos, nos estudos de Benjamin sobre o flâneur, elaborado em relação à Paris do século XIX, há algo intrinsecamente problemático na tentativa de localizar esses tipos isoladamente, como definidores da metrópole como tal. (Isto é ainda mais óbvio quando evocamos a heterogeneidade das formas emergentes e não ocidentais de urbanização metropolitana e sua relação com a Europa ou com as formas norte-americanas. O urbano não é, claro, e nunca foi - uma forma exclusivamente - ou mesmo predominantemente - ocidental). Como conceito, a metrópole é articulável apenas como um sistema dinâmico de relações técnicas ou de referências, de conectividade e de produção. É isso que é abordado através de figuras de organização metropolitana e de relações sócio espaciais 
diferentes, formalmente precisas, transdisciplinares. Figuras comuns que encontram em Lefebvre e Simmel, em Benjamim e outros: aglutinação, colagem, constelação, rede e assim por diante. É evidente que a aceitação de tais figuras deve agora ser pensada em relação à mudança da natureza social e espacial das relações nas quais as tendências da urbanização global contemporânea se desenrolam. Seria preciso pensar aqui, por exemplo, em que medida a atual figura hegemônica da rede - "hoje vemos redes em todos os lugares", escrevem Hardt e Negri ${ }^{47}$ - e sua própria reivindicação à mediação conceitual de uma totalidade social emergente, pode ou não ser entendida como marca da extensão efetiva de uma lógica metropolitana produtiva, como Cacciari sugere: a reunião simultânea de pontos distantes e justapostos, que já não é realizada dentro da totalidade espacial contínua das metrópoles mais ou menos discretas - e que agora formam um processo de urbanização emergente, diferenciado e total em escala planetária. ${ }^{48}$

Deixo isto como uma questão em aberto. Certamente, na medida em que o espaço social de troca parece agora abranger (ainda que de modo desigual) todo o planeta - uma dimensão global para a abstração da formavalor que leva adiante (espacial e fenomenologicamente) a negação determinada do "valor específico" e da "incomparabilidade" do lugar - isso pode sugerir, tal como abordado no início deste artigo, que a metrópole está em processo de ser negada como a forma contemporânea do urbano, deslocada por algumas lógicas novas de produção espacial. Daí a profusão de novos conceitos em estudos urbanos que buscam apreender essa mudança, começando, sem dúvida, com Soja em 'Postmetropolis' - no qual ele aponta uma Quarta Revolução Urbana. No entanto, na medida em que o conceito de metrópole como forma pura já se apresenta em relação a um horizonte projetado da equivalência absoluta, ele não parece redundante no que se refere a um conhecimento adequado da forma urbana contemporânea. Se assim for, pode agora aparecer de duas maneiras diferentes (mas interrelacionadas): por um lado, como os "elementos" dispersos de uma rede global interconectada - uma rede que é constitutiva da forma particular e da "experiência" de qualquer metrópole particular ${ }^{49}$ - e, por outro, como a forma básica e generalizada da própria rede, que é portanto, conceitualmente moldada como uma espécie, de "metrópole virtual" (para tomar emprestada uma frase de Koolhaas) ${ }^{50}$ historicamente nova e universalmente "irradiada". Talvez o jogo recíproco entre estes diferentes níveis e suas formas "quase lógicas", possam definir conceitualmente a problemática urbana contemporânea mundial. No mínimo, parece ser possível argumentar que a metrópole ainda se apresenta, de modo produtivo, como a mutação de uma "figura hegemônica" - um ponto de mediação com as formas mais gerais de experiência social e prática - conceitualmente homóloga às tendências gerais de desenvolvimento do capitalismo urbano global.

\section{Valor, abstração e a diferença}

Historicamente, a metrópole designa uma estrutura quase universal. Se o meu argumento é aceito, ela designa, mais especificamente, uma forma 'real' de abstração espacial que é constitutiva de formações particulares da experiência do patrimônio histórico. No entanto, precisamente por isso, é preciso colocar em questão a relação exata entre a metrópole e a forma-valor 
(como estruturação de abstração da modernidade capitalista). Então, nossa análise parece sugerir que a metrópole é, conceitual e praticamente, subordinada nessa relação - interna ao seu campo, suas possibilidades ou nada mais que uma determinação "específica" (especialmente significativa) de sua forma pura de intermutabilidade? Ou há alguma estrutura mais complexa e variante de determinação em jogo aqui? ${ }^{51}$

Pode haver pouca dúvida de que são os processos socioeconômicos das relações capitalistas de produção e troca, dominados pela forma-valor, que constituem historicamente, e continuam a constituir a metrópole. Não há metrópole sem a hegemonia do capital. No entanto, essa hegemonia não é total ou completa. Pois o próprio capitalismo não é redutível à lógica da acumulação de capital, nem à abstração específica da forma-valor. Ele está - o mesmo ocorre com as modernas formas urbanas - sempre articulado com outras formas e relações sociais "não capitalistas". De fato, ele não pode se reproduzir sem tais formas, mesmo se as submete a uma reformulação. $\mathrm{Na}$ verdade, em parte alguma isso é mais claro do que na reformulação contemporânea da metrópole, sujeita a uma generalização que não mais restringe seu 'terreno' aos lugares clássicos como a Berlim de Simmel, a Paris de Benjamin ou a Viena de Musil, mas que poderia "incorporar" outros como Lagos, Mumbai, São Paulo e Kuala Lumpur. Pode-se até sugerir, como Nanne de $\mathrm{Ru}$, colaborador de Koolhaas, que enquanto "a Europa já foi o berço da Metrópole", seu futuro "será definido no mundo em desenvolvimento". ${ }^{52}$ É claro que, politicamente, se isto for entendido como um recurso apenas para a oposição residual das chamadas formas culturais e sociais pré-capitalistas, seu efeito será pouco mais do que Tafuri chama de ação de 'retaguarda', o pretexto para um caminho reativo de teoria, a criação do local ou o genius loci, e também uma falha no confronto com a "verdade" da metrópole, de modo a compreender historicamente o caminho percorrido. No entanto, se a metrópole, de fato, apresentar-se como "forma pura", vazia de qualquer conteúdo específico (incluindo a política específica ou a de conteúdo cultural), as possibilidades de prática produtiva do sistema metropolitano de conectividade não estão esgotadas pela sua estrutura abstrata de condições de acumulação de capital. As formas relacionais determinadas pela permutabilidade são também, no mínimo, sujeitos de uma espécie de desvio em potencial, como as histórias de conflitos urbanos a partir da Comuna de Paris. (Uma igreja pode, na estrutura formal da equivalência universal, tornar-se um café, uma galeria de arte, um conjunto de apartamentos, um estúdio de gravação ou algo assim.)

É um sinal revelador da ressonância da problemática associada a um determinado conceito o fato de encontrar-se absorvida dentro da contínua luta de Hardt e Negri para dar substância à ideia de multidão. Vale notar então que, assim como citou em Multidão a "urbanização da luta política e conflito armado na década de 1970", como um elemento-chave na "construção de novos circuitos de comunicação e novas formas de colaboração social", Negri, em um ensaio publicado em 2002, intitulado "A multidão e a Metrópole", descreve como "internamente antagônicas" as configurações espaciais da metrópole como substituindo o privilegiado "lugar" anteriormente concedido à fábrica (mesmo se prolongando como a "fábrica social" de Tronti), como o local fundamental da produção social e do conflito. ${ }^{53}$

No entanto, do ponto de vista politico e também filosófico, as afirmações acima devem sugerir um certo conjunto de complicações sobre a natureza 
desse antagonismo, bem como as suas novas formas sociais de colaboração, que Negri procura articular, assim como faz Lefebvre em seus estudos sobre a abstração e o ambiente urbano. Novas relações sociais exigem um novo espaço, como Lefebvre celebremente escreveu em A Produção do espaço; dando a esse espaço, em uma formulação clássica dialética, um nome célebre e marcante: espaço diferencial. O espaço abstrato "relaciona-se negativamente a algo que carrega dentro de si e que procura surgir a partir dele": as sementes utópicas de um novo espaço que são abrigadas por "contradições específicas" do espaço abstrato. Formal e quantitativa, a "abstração ruim" do espaço abstrato é, como tempo de trabalho, o que apaga as distinções. A metrópole é, portanto, o lugar de um conflito necessário e irredutível:

Hoje, mais do que nunca, a luta de classes se inscreve no espaço. Na verdade, é a luta que impede o espaço abstrato de assumir a totalidade do planeta e omitir as diferenças. Apenas a luta de classes tem a capacidade de diferenciar, gerar diferenças que não são intrínsecas ao crescimento econômico qua estratégia, "sistema" ou "lógica". 54

Embora as formulações dialéticas de Lefebvre estejam distantes das de Negri, é evidentemente em direção a tal concepção de conflito que Negri guiou seu trabalho recente. É a positividade do "trabalho vivo", na figura da multidão, que gera a "força criativa" do "poder autônomo", suas diferenças e a multiplicidade no espaço antagônico na metrópole 'molecular'. Retomando a celebração de Rem Koolhaas do que ele chama metrópole delirante - mas talvez com uma dívida não reconhecida também de seu ex-colaborador da revista Contropiano, Cacciari - Negri encontra lá, assim como Lefebvre, os sinais de uma luta contra a "abstração ruim" imperial do espaço abstrato. Como um espaço híbrido, a metrópole produz novos espaços de autonomia que semeiam as sementes das "novas relações sociais e novas formas de cooperação".

Dificilmente se pode discutir tal possibilidade, assim como o reconhecimento das formas fundamentais de divisão social inscrita no espaço urbano contemporâneo no qual essa visão se articula. No entanto, a partir das perspectivas da discussão de abstração descritas acima, provocamos algumas perguntas difíceis (não só para Negri e Lefebvre, mas também para concepções pós-modernas pervasivas de uma "cosmópole" porvir). Negri e Lefebvre são citados aqui porque são ambos relativamente livres do que tem sido uma nostalgia historicamente comum da esquerda pelas formas sociais da vila ou cidade. Cada um sabe que a lógica da metrópole não pode simplesmente ser contornada, apenas ativa e produtivamente encetada. No entanto, ambos os autores ainda parecem estar conectados a uma ideia projetada da diferença que, de alguma forma se encontra além da abstração, por si só. Sobre espaço diferencial, Lefebvre escreve:

acentua as diferenças ... [mas] também restaura a unidade para o que o espaço abstrato rompe - para as funções, elementos e momentos da prática social. Ele vai colocar um fim a essas localizações que quebram a integridade do corpo do indivíduo, o corpo social, o corpus de necessidades humanas, e o corpus de conhecimento. Pelo contrário, ele irá distinguir o espaço abstrato que tende a identidade. ${ }^{55}$ 
Para Lefebvre, o espaço diferencial refere-se à negatividade da abstração. No entanto, não seria um determinado espaço abstrato a condição, ou de fato a forma necessária de tal espaço diferencial? ${ }^{56}$ De fato, sem certas estruturas e experiências de abstração, tal espaço de conectividade diferencial ou "unidade" social poderia ser concebível de alguma forma? Esta parece ser uma questão particularmente pertinente no contexto da forma urbana contemporânea. Isto sugere que a oposição entre o "abstrato" e "concreto" precisa ser repensada. Pois o espaço abstrato é um lugar positivo da produção de experiências constitutivas de novas formas "concretas" geradoras de relacão espacial de significado social. Não é simplesmente, como supõe a recepção do trabalho de Lefebvre, uma mera forma de representação do mascaramento conceitual ou desconhecimento de alguns conteúdos imutáveis do que seria uma "experiência de vida" real, múltipla e concreta. ${ }^{57} \mathrm{Na}$ metrópole, Simmel escreve que o que aparece nas relações espaciais "diretamente como dissociação é, na realidade, apenas uma de suas formas elementares de socialização." 58 Tal é a específica dialética negativa metropolitana da modernidade capitalista, que constitui a forma urbana do ensaio de Simmel e de suas próprias antinomias definitivamente inconciliáveis.

Nesse sentido, politicamente, é interessante considerar que hoje, tratase menos uma simples questão de "diferença" versus "abstração" - os traços de uma oposição binária passível de desconstrução - ou se é possível conceber uma relação entre diferença e abstração além daquela constituída pela "forma-valor". Se sim, como então podemos conceber hoje o que a Carta Mundial do Direito à Cidade, elaborada durante o Fórum Social das Américas em 2004, postula sobre o potencial do urbano? Como a Carta reconhece, se as divisões sociais da metrópole favorecem o surgimento do conflito urbano, suas formações contemporâneas também significam que este é "geralmente fragmentado e incapaz de produzir uma mudança significativa nos modelos de desenvolvimento correntes". ${ }^{59}$ Como mostra o recente relatório da ONUHabitat sobre assentamentos humanos, a urbanização global contemporânea é dominada pela difusão espacial de favelas (slums), em que agora vive quase um bilhão de pessoas, aproximadamente $32 \%$ da população urbana global.. $\mathrm{Na}$ África Subsaariana a proporção é de mais de $72 \%$. O valor global pode dobrar no prazo de 30 anos. Em todo o mundo, a pobreza está se tornando urbanizada ${ }^{60}$ Esse desenvolvimento continua a ser determinado pelos distintos e contraditórios modos de abstração da forma valor, mas de acordo com as lógicas espaciais que não são mais aquelas do início século XX.

Em 1848, Marx viu as "cidades grandes" como uma forma de relação em que a força do proletariado poderia crescer, e ele sentia que essa força poderia crescer mais. ${ }^{61}$ No entanto, como Mike Davis observa, a recente expansão da população urbana do mundo em desenvolvimento, "massivamente concentrado num mundo favela", carece de algo como o poder econômico estratégico do trabalho socializado. Lutas aqui tendem a ser "episódicas e descontínuas", refletindo uma reconfiguração do próprio 'local' como fugidio, transitório e migrante ${ }^{62}$ Que possibilidades de emancipação podem surgir através dessas novas formas metropolitanas de relação e interconexão permanece opaco e imprevisível. No entanto, é, finalmente, na tentativa de elaborar tais possibilidades que o conceito de metrópole deve encontrar sua real necessidade teórica. 
Notas:

Professor da School of Social Sciences, Humanities \& Languages da University of Westminster em Londres, Inglaterra.

1. Henri Lefebvre, Urban Revolution (1970), trad. Robert Bononno, University of Minnesota Press, Minneapolis and London, 2003, p. 5, grifos meus.

2. John Eade and Christopher Mele, 'Introduction:Understanding the City', in Understanding the City: Contemporary and Future Perspectives, Blackwell, Oxford, 2002, p. 3.

3. Ver Andy Merrifield, Metromarxism: A Marxist Tale of the City, Routledge, London and New York, 2002, p. 3.

4. Manuel Castells, The Urban Question: A Marxist Approach, Edward Arnold, London, 1977.

5. Para um padrão sobre a expressão da metrópole como alegoria ou figura privilegiada da modernidade, ver lain Chambers, Border Dialogues: Journeys in Postmodernity, Routledge, London and New York, 1990, p. 55, 112.

6. Henri Lefebvre, Right to the City, in Writings on Cities, trad. e ed. Eleanore Kofman and Elizabeth Lebas, Blackwell, Oxford and Malden MA, 1996, p. 86.

7. Jean-François Pradeau, Plato and the City: a New Introduction to Plato's Political Thought, trad. Janet Lloyd, Exeter University Press, Exeter, 2002, p. 5.

8. Aristotle, The Politics, trad. T.A. Sinclair, rev. Trevor J. Saunders, Penguin, London, 1992, p. 59 [I ii], 54 [I i].

9. Pradeau, Plato and the City, p. 43.

10. Ver Manfredo Tafuri, Architecture and Utopia: Design and Capitalist Development, trad. Barbara Luigia La- Penta, MIT Press, Cambridge MA, 1976, p. 1-40.

11. Seguindo e estendendo os argumentos de Jane Jacobs, bem como apoiando-se na pesquisa arqueológica de Kathleen Kenyon e Mellaart James, Soja afirma a existência de uma Primeira Revolução Urbana com início no Sudoeste da Ásia há mais de 10.000 anos: o desenvolvimento de assentamentos urbano pré-agrícolas de caçadores, coletores e comerciantes que se identificam com as formas urbanas encontradas em Jericó, no Vale do Jordão e Catal Huyuk no sul da Anatólia. Ver Edward W. Soja, Postmetropolis: Critical studies of cities and regions, Blackwell, Oxford, 2000, p 19-49.

12. Em sua origem no século XIX, a mudança histórica de que se trata aqui pode ser mais claramente registrada, em inglês, por termos que envolvem o uso figural, na medicina e na história natural, bem como por uma série de novas apropriações em torno da década de 1850: "metropolitaneously", "metropolitanism", "metropolitanize". Mais significativamente, esses novos termos, cada um se relacionam com um sentido relativamente novo da palavra "metropolitana" em si, como a designação de diferentes formas de "idéias", "espírito" ou "modos". É a esta luz, também, que teríamos que pensar a palavra alemã Grossstadt (literalmente "grande cidade") termo usado no famoso ensaio de Simmel - como implicando algo mais que a mera designação quantitativa que parece representar. Embora seja verdade que, na Alemanha como em outros lugares, o fim do século XIX assistiu a um debate sobre a definição estatística de uma metrópole (em geral 100.000 pessoas), este debate também envolve suas dimensões crucialmente qualitativas.

13. Para se aprofundar na introdução de Cacciari e na teoria da metrópole, ver Gail Day, 'Strategies in the Metropolitan Merz', nesta edição da RP; David Cunningham, 'The Phenomenology of Non-Dwelling: Massimo Cacciari, Modernism and the Philosophy of the Metropolis', Crossings 7, 2004; e Patrizia Lombardo, 'Introduction: The Philosophy of the City', in Massimo Cacciari, Architecture and Nihilism: On the Philosophy of Modern Architecture, trans. Stephen Sartarelli, Yale University Press, New Haven and London, 1993. Como Lombardo mostra, o trabalho de Cacciari, nos anos 1970 e início de 1980, é constituído precisamente como uma filosofia da metrópole.

14. Cacciari, Architecture and Nihilism, p. 199-200.

15. As citações de Bücher e Scheffler encontram-se em David Frisby, Cityscapes of Modernity, Polity Press, Cambridge, 2001, pp. 131-9, 266.

16. Cacciari, Architecture and Nihilism, p. 23. Se a canônica expressão do pós-guerra de tal utopia regressiva é encontrada na obra de Lewis Mumford, sua articulação mais influente é dada pelos escritos de Richard Sennett. Ver Flesh and Stone: The Body and the City in Western Civilization, Faber \& Faber, London and Boston, 1994. Para Cacciari, mesmo que Simmel nos dê as ferramentas para compreendê-la, ele finalmente volta para sua própria reconstrução "ético-sentimental' da cidade dentro da metrópole. 
17. Lombardo Patrizia, Cities, Words and Images: From Poe to Scorsese, Palgrave, London and New York, 2003, p. 72-9; Philippe Lacoue-Labarthe, Heidegger, Art and Politics, trans. Chris Turner, Blackwell, Oxford, 1990, p. 65.

18. Lefebvre, Urban revolution p. 2.

19. Cacciari, Architecture and Nihilism, p. 3 (grifo meu). Vale a pena dizer que, para Simmel, parece claro que o problema chave de sua filosofia não apareceu primeiramente como o da metrópole, mas como o do dinheiro.

20. Ludwig Wittgenstein, § 18 Investigações Filosóficas. Tradução de José Carlos Bruni . Abril CulturalRobert J. Ackermann, Wittgenstein's City, University of Massachusetts Press, Amhurst MA, 1988.

21. Nesta unidade de saberes, formada em torno de uma filosofia que, como um produto da divisão da polis de trabalho, "torna-se uma atividade especializada...[ainda] não torna-se fragmentada, vê Lefebvre, Right to the city, p. 87-9. Para uma leitura que enfatiza a cidade de Wittgenstein como uma descrição historicamente específica de Viena da virada do século, ver Frisby, Cityscapes of Modernity, p. 182-8. Ver também Allan Janik e Stephen Toulmin, Wittgenstein's Vienna, Simon \& Schuster, New York, 1973.

22. É nestes termos que Cacciari relaciona a heterogeneidade dos jogos de linguagem nos últimos trabalhos de Wittgenstein com a arquitetura metropolitana de seu contemporâneo vienense Adolf Loos.

23. Lefebvre, Urban Revolution, pp 63-4.

24. Ibid., P. 65.

25. Ibid., P. 53.

26. Ibid., P. 64.

27. Este é um argumento que eu desenvolvo, em parte, a partir dos argumentos de Peter Osborne para uma "prática filosófica interdisciplinar". Ver Philosophy in Cultural Theory, Routledge, London and New York, 2000, pp. 16-19. As disputas entre o "abstrato" e "concreto" repetem uma problemática padrão de um certo desenvolvimento do pensamento marxista, que muitas vezes definiu-se pela suspeita do filosófico e do conceitual. Para exemplificar uma discussão recente que discorre mais sobre o "concreto", ver Philip Wood, "materialismo histórico", em Georgina Blakely e Valerie Bryson, eds, Marx and Other Four- Letter Words, Pluto, London, 2005, p. 12-18. Na luta contra tal argumento, entretanto, o objetivo não seria defender o "abstrato" contra o "concreto", mas sim para sugerir a necessidade do social, como estritamente filosófico, ou mesmo desconstruir a oposição entre o "abstrato" e "concreto".

28. Lefebvre, Urban revolution, p. 118-19; Henri Lefebvre, The production of space, trad. Donald Nicholson-Smith, Oxford, Blackwell, 1991, p. 101.

29. Lefebvre, The production of space, p. 100.

30. Karl Marx, Grundrisse, trad. Nicholaus Martin, Penguim, Harmondsworth, 1973, p. 100.

31. Daniel Bensaïd, Marx for Our Times, trad. Gregory Elliot, Verso, Londres e Nova York, 2002, p. 254.

32. Peter Osborne, "The Reproach of Abstraction", Radical Philosophy 127, September/October 2004, p. 21-8. Osborne propõe aqui uma distinção, derivada de Hegel, entre o "real" (real) e "atual" (wirklich), reservando o último termo, em contraponto à "realidade" meramente empírica dos universais abstratos do entendimento, para "os aspectos da abstração auto-realizada", como um capital de auto-valorização, "constitutivos da totalidade como um todo (P. 27).

33. Lefebvre, The production of space, p. 101.

34. Christopher J. Arthur, 'The Spectral Ontology of Value', Radical Philosophy 107, May/June 2001, p. 32.

35. Se a forma urbana moderna, que busco abordar pelo conceito de metrópole, pode ser entendida analiticamente como a formação de uma abstração real - como uma forma eficaz de unidade do espaço social que "não repousa em qualquer conteúdo pré-determinado comum"- a crítica inicial de Castells sobre Lefebvre como sendo um mero "metafísico" urbano poderia ser dita neste sentido específico, não mais "metafísica" do que o próprio conceito de "valor" de Marx. Ver Manuel Castells, "Citizen Movements, Information and Analysis: An Interview", City 7, 1997, pp. 146-7. Sobre a metafísica do conceito de valor de Marx, ver Arthur, "Spectral Ontology", p. 33.

36. Ver Osborne, "Reproach of Abstraction", p. 28. Este tipo de formulação também levanta uma série de questões mais amplas sobre a afinidade entre a abstração "filosófica" e a abstração da forma-valor. Tal afinidade, segundo Adorno, poderia continuar a dar às categorias idealistas de Hegel uma importância homóloga ao idealismo real na forma capitalista. No 
entanto, uma análise adequada dessas questões - que teria impacto sobre as questões da transdisciplinaridade levantadas aqui - está além do escopo deste artigo.

37. Lefebvre, The production of space, p. 102.

38. Arthur, 'Spectral Ontology', p. 34.

39. Ibid., P. 40, 35.

40. Georg Simmel, 'The Metropolis and Mental Life', trad. Hans Gerth, in Simmel on Culture:

Selected Writings, Sage, London, Thousand Oaks CA and Delhi, 1997, p. 176, 178.

41. Cacciari, Architecture and Nihilism, p. 9.

42. Ibid., P. 4.

43. Ver a seção "Extreme Unity in Plato's Republic" in Aristotle, Politics, p. 103-12 [II ii - II v]:

"A polis consiste não apenas de uma pluralidade de homens, mas de diferentes tipos de homens (104); "excessivo esforço de unificação é uma coisa negativa em uma polis "(105).

44. Tenho procurado refletir sobre o significado da arquitetura como uma forma de conhecimento crítico do urbano, mas também podemos pensar, por exemplo, na importância do romance, no início dos anos século XX, nestes termos. Ver David Cunningham, 'Architecture as Critical Knowledge' in Mark Dorrian, Murray Fraser, Jonathan Hill and Jane Rendell, ed., Critical Architecture, Routledge, London and New York, 2006.

45. Lefebvre, The production of space, p. 86.

46. Ver Cunningham, "The Phenomenology of Non-Dwelling"; Massimo Cacciari, 'Eupalinos or Architecture', trad. Stephen Sartarelli, Oppositions 21, 1980.

É interessante notar, a este respeito, a clareza heideggeriana de conceito de "habitação" a ser encontrado durante a revolução urbana.

47. Michael Hardt e Antonio Negri "Multitude", Hamish Hamilton, London, 2004, p. 142. A figura da rede tem em si uma longa história no discurso urbanista, das grades até os conceitos modernistas utópicos de 1960, tais como o Plug-In da Archigram City.

48. Cacciari, 'Eupalinos or Architecture', p. 114.

49. Sou grato a Peter Osborne por esta formulação.

50. Koolhaas usa essa frase em particular em suas discussões sobre o projeto Euralille, um ponto nodal de conectividade que, quase por acidente, torna-se fundamental para uma 'metrópole virtual se espalhar de maneira irregular', onde 60 ou 70 milhões de pessoas vivem hoje aproximadamente a noventa minutos de trem um do outro. Isto reflete um fascínio mais geral por parte de Koolhaas pela "dispersão" da forma urbana que caracteriza tais evoluções díspares como o Delta do rio das Pérolas na China e o 'Hollocore' que liga Bruxelas, Amsterdan e o vale do Ruhr, na Alemanha. O ponto chave aqui é que, a princípio, "dispersão" e "virtualidade" não têm nenhum limite natural.

51. Meu agradecimento especial a Martin Stewart por sua ajuda (e insistência) na formulação destas perguntas.

52. Nanna de Ru, Hollocore, em OMA / Rem Koolhaas, ed., Content, Taschen, Colônia, 2004, p. 336.

53. Hardt e Negri, Multitude, p. 81; Antonio Negri, "La moltitudine e la metrópole, on-line em www.mailarchive.com.br/autistici.org/msg00105.html@rekombinant, acessado em 01/03/2005. Veja também Alberto Toscano, "Factory, Território, Metropolis, Empire', Angelaki, vol. $9^{\circ}, \mathrm{n}^{\circ} .2$, Agosto de 2004, pp 197-216.

54. Lefebvre, The production of space, pp 59, 50, 52, 14, 49, 55.

55. Ibid., P. 52.

56. Ibid., P. 50.

57. Lefebvre em algum momento parece sugerir que a abstração é simplesmente oposição às experiências "vividas", em parte porque ele sempre tende a abordar a "ontologia" do espaço abstrato através de noções de representação, se os diagramas de planejamento urbano e arquitetura modernista ou as concepções filosóficas e matemáticas do espaço podem ser apreendidos em um único ato de intuição por causa do seu caráter homogêneo. Ver Lefebvre, The production of space, p 14, 51.

58. Simmel, "Metropolis", p. 180.

59. Carta Mundial do Direito à Cidade, online em www.choike.org/nuevo eng/informes/2243.html.

60. The Challenge of Slums: Global Report on Human Settlements, UN-Habitat, London, 2003.

61. Karl Marx, The Communist Manifesto, Penguin, Harmondsworth, 1967, p. 84, 89.

62. Mike Davis, 'Planet of Slums', New Left Review 26, March/April 2004, p. 27, 29. 
